\title{
Uso de cianoacrilato versus cimento cirúrgico no reparo de áreas doadoras de enxerto gengival livre: relato de caso
}

\section{Use of cyanoacrylate versus periodontal dressing in the healing of donor sites in free gingival grafts: a case report}

\author{
Ana Emília Farias Pontes ${ }^{1}$, Celina Cavaguti ${ }^{1}$, Rafaela Videira Clima da Silva ${ }^{1}$, Juliana Rico Pires ${ }^{1}$, \\ Elizangela Partata Zuza ${ }^{1}$, Fernando Salimon Ribeiro ${ }^{1}$ \\ ${ }^{1}$ Curso de Odontologia, Centro Universitário da Fundação Educacional de Barretos (UNIFEB) - Barretos \\ (SP), Brasil.
}

\begin{abstract}
Resumo
O uso de adesivos à base de cianoacrilato vem aumentando na Odontologia. Isso se deve ao fato de ser um método indolor, rápido e de fácil execução. O objetivo deste estudo foi relatar um caso clínico controlado utilizando o etil-cianoacrilato como agente selador e hemostático em uma cirurgia periodontal no palato. A paciente de 59 anos foi encaminhada para ser submetida à extração dos incisivos superiores. Então, o selamento do alvéolo foi planejado usando enxerto gengival livre obtido de duas áreas doadoras do palato que se estendiam até o rebordo edêntulo. Ambas as áreas foram suturadas com fio de nylon, das quais uma recoberta por cianoacrilato e a outra por cimento cirúrgico periodontal. Os sítios cirúrgicos foram fotografados e analisados em acompanhamentos pós-operatórios realizados aos 7, 14, 28 e 35 dias. Em todos os períodos, constataram-se semelhanças entre o processo de reparo das duas áreas. A epitelização completa foi observada no $28^{\circ}$ dia de acompanhamento. Com base nesses achados, sugere-se que o cianoacrilato não trouxe benefícios adicionais à área doadora de enxerto de tecido conjuntivo, visto que o padrão de reparo foi muito semelhante ao do cimento cirúrgico. Entretanto, seu uso pode ser justificado como alternativa ao cimento pelo baixo custo, rapidez e facilidade de aplicação.
\end{abstract}

Palavras-chave: mucosa bucal; palato; transplante autólogo; técnicas de fechamento de feridas.

\begin{abstract}
The use of cyanoacrylate adhesives has been increasing in Dentistry due to the fact that it is a painless method, fast and easy to perform. The objective of this study was to report a controlled clinical case in which ethyl cyanoacrylate was used as sealant and hemostatic agent in a periodontal surgery performed on the palate. The 59-year-old patient was referred to extraction of the upper incisors. The sealing of the sockets was planned using free gingival graft obtained from two donor sites on the palate extending to the edentulous ridge. Both areas were sutured with nylon threads; one was covered with cyanoacrylate and the other with a periodontal dressing. The sites were photographed and analyzed for post-operative monitoring after $7,14,28$, and 35 days. At all of the times, similarities were observed between the healing processes of both areas. Complete epithelialization was observed on the $28^{\text {th }}$ day of monitoring. Based on these findings, it is suggested that the cyanoacrylate did not bring additional benefits to the area of donor tissue grafts, considering that the standard repair was very similar to the surgical dressing. However, its use can be justified as an alternative to periodontal dressing due to its low cost, speed, and ease of application.
\end{abstract}

Keywords: mouth mucosa; palate; transplantation, autologous; wound closure techniques.

Autor para correspondência: Ana Emília Farias Pontes - Centro Universitário da Fundação Educacional de Barretos (UNIFEB), Avenida Prof. Roberto Frade Monte, 389 - CEP: 14783-226 - Barretos (SP), Brasil - E-mail: anaemiliapontes@yahoo.com.br

Recebido em: 13 de novembro de 2015

Aceito para publicação em: 13 de abril de 2016

http://dx.doi.org/10.4322/1980-0029.192015 


\section{Introdução}

As suturas convencionais apresentam um maior índice de falhas quando comparadas às técnicas que utilizam adesivos tissulares (MATTICK, 2002). Diferentes tipos de cianoacrilatos têm sido usados para fechamento de retalhos, diferindo-se pelo comprimento da cadeia lateral, tais como: metil $\left(\mathrm{R}=\mathrm{CH}_{3}\right)$, etil $\left(\mathrm{R}=\mathrm{C}_{2} \mathrm{H}_{5}\right)$, butil e isobutil $\left(\mathrm{R}=\mathrm{C}_{4} \mathrm{H}_{9}\right)$. Quanto menor for a cadeia lateral, menor sua histotoxicidade e seu tempo de reparo (WEBER e CHAPMAN, 1984). De forma geral, as principais características desses adesivos incluem a capacidade de hemostasia de vasos periféricos e selamento tecidual, constituindo um método indolor, rápido, eficiente por seu alto poder de adesão, de fácil execução e que proporciona mínima cicatriz.

Esses adesivos, que vêm sendo usados desde 1959 por Coover e outros pesquisadores, destacam-se ainda por sua capacidade de autopolimerização quando em contato com diferentes substratos, formando ligações muito fortes com a pele e a mucosa (VELAZCO et al., 2008). Os adesivos de butil-2-cianoacrilato (SuperBonder ${ }^{\circledR}$, Locite, Henkel Ltda., Itapevi, SP, Brasil) e etil-cianoacrilato (Hystoacril ${ }^{\circledR}$, Tissue Seal, Ann Arbor, MI, EUA) são empregados em vários ramos da Medicina e Odontologia por apresentarem baixo grau de histotoxicidade, rápida cicatrização, por possuírem efeito bacteriostático e hemostático melhor quando comparados a suturas convencionais. Ueda et al. (2004), que avaliaram o butil-2-cianoacrilato quanto à esterilidade e atividade biocida, encontraram resultados que comprovam a atividade bacteriostática desse adesivo em cepas de Staphylococcus aureus e Staphylococcus xylosis. Saska et al. (2009), ao compararem a compatibilidade do etil-cianoacrilato e butil-cianoacrilato em dorso de ratos, observaram que esses adesivos, quando implantados no subcutâneo, promoveram reação inflamatória até 120 dias - mais intensa com o uso do etil-cianoacrilato.

$\mathrm{O}$ uso de adesivos à base de cianoacrilato na Medicina tem sido relatado para selamento de tecidos moles, cirurgias cosméticas, cirurgias vasculares e reconstrução de cabeça e pescoço, tais como em soalho orbitário, enxertos ósseos, união de fendas palatinas e lacerações faciais pediátricas (HABIB et al., 2013; VIERHOUT et al., 2014). $\mathrm{Na}$ Odontologia, seu uso foi relatado para selamento do canal protético na ausência de uma restauração definitiva, evitando, assim, reinfecções da porção obturada do canal radicular (BIER et al., 2003). Além disso, experimentalmente, foi empregado na estabilização de membrana colágeno sobre enxerto em bloco, em modelo de calota craniana de ratos (REZENDE et al., 2014).

Na periodontia, Farnoush (1978) enfatizou ainda que o cianoacrilato não é volumoso, portanto não interfere com o uso de próteses, pode ser usado ao redor de dentes unitários, reduz a dor pós-operatória, não induz o crescimento de tecido de granulação e acelera o processo de cicatrização. Bhaskar et al. (1966) destacam que seu custo é baixo em relação às suturas. Entretanto, pode atrapalhar a cicatrização se esse adesivo infiltrar-se sob um retalho ou dentro dos tecidos produzindo tecido de granulação.

Seu emprego foi descrito para: promover rigidez à membrana de PTFE em cirurgia de regeneração tecidual guiada (ECHEVERRÍA e MANZANARES, 1995); como adesivo para o selamento do sulco gengival de forma a manter o chip de liberação local de clorexidina em posição e assegurar sua retenção (CARVALHO et al., 2007); no tratamento de hipersensibilidade dentinária; para ajudar na estabilização do enxerto gengival livre em áreas de exposição radicular (OLIVEIRA et al., 2013) ou mesmo após a realização da sutura para melhor fixação do retalho (BUTLER, 2003). Experimentalmente, o cianoacrilato também vem sendo usado no selamento de lesões periodontais tratadas em humanos (KULKARNI et al., 2007) e induzidas em ratos (CHANG et al., 2012).

Poucos estudos demonstram a aplicabilidade do etil-cianoacrilato nas áreas doadoras do enxerto, como o palato (BHASKAR et al., 1971; FORREST, 1974; GRISDALE, 1998; BARBOSA et al., 2008). Sendo assim, o objetivo deste trabalho foi relatar um caso clínico controlado utilizando o etil-cianoacrilato como agente selador e hemostático em uma cirurgia periodontal no palato.

\section{Relato de Caso}

Paciente S.M.M.S, 59 anos, gênero feminino, foi encaminhada para clínica Odontológica do Centro Universitário da Fundação Educacional de Barretos (UNIFEB), no Estado de São Paulo, para ser submetida à extração dos incisivos superiores por razões protéticas. Com o objetivo de promover a preservação do rebordo pós-extração, foi planejado o selamento do alvéolo com enxerto gengival livre obtido do palato e rebordo edêntulo, seguindo a 
técnica descrita por Stimmelmayr et al. (2010) e embasada em revisão bibliográfica previamente publicada (PONTES et al., 2014). O termo de consentimento foi obtido, e este relato foi realizado em conformidade com os princípios éticos da Organização Mundial da Saúde.

$\mathrm{Na}$ anamnese, a paciente reportou ser tabagista (em média 15 cigarros por dia), hipertensa (pressão arterial 130x $90 \mathrm{mmHg}$ ), e fazer uso de medicamento para controle da hipertensão (Losartana Potássica $50 \mathrm{mg}$, a cada 24 horas). Relatou ainda ter sido submetida há poucos meses a tratamento periodontal básico em função do diagnóstico de gengivite.

No dia da cirurgia, foi realizada a assepsia extrabucal com clorexidina a 2\%, e a intrabucal, com clorexidina a $0,12 \%$. Para extração dos elementos de 12 a 22, foi realizada a anestesia infiltrativa com articaína a 2\% com epinefrina 1:100.000 (Articaine, DFL, Rio de Janeiro, Brasil), seguida de incisão intrasulcular. Os dentes foram cuidadosamente removidos com o auxílio de periótomo e fórceps (Figura 1a). O retalho foi gentilmente descolado na vestibular e lingual apenas o suficiente para acomodar o enxerto gengival livre.

Diante da disponibilidade de tecido no rebordo edêntulo no terceiro sextante, optou-se por essa área como doadora (Figura 1b). O tamanho e o formato do enxerto foram avaliados usando um mapa criado com papel esterilizado. A anestesia infiltrativa foi realizada em fundo de sulco, rebordo e palato, e então o mapa foi posicionado na área doadora para guiar a incisão, realizada com lâmina de bisturi $15 \mathrm{c}$ montada em cabo \#3. O enxerto foi removido de duas áreas, uma mais mesial e outra mais distal, com tamanhos e formatos semelhantes e profundidade aproximada de $2 \mathrm{~mm}$ (Figura 2a).

Ambas as áreas doadoras foram suturadas de forma contínua com fio de nylon 4.0. Em seguida, a área mais distal foi recoberta por cianoacrilato (Henkel Loctite adesivos Ltda., Itapevi, SP, Brasil),

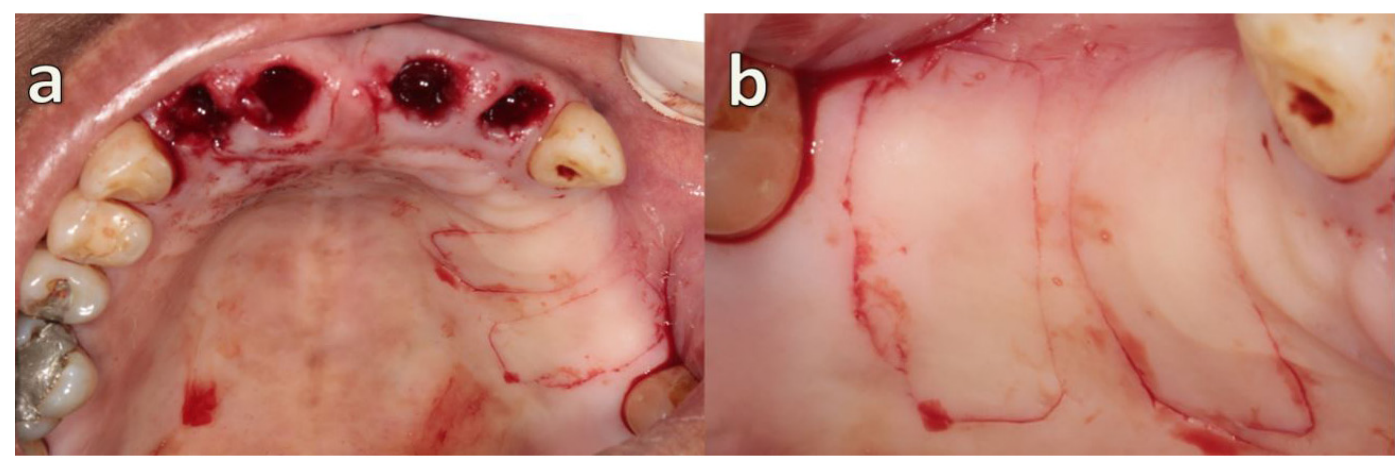

Figura 1. Aspecto clínico inicial após exodontia dos incisivos superiores e delineamento das duas áreas doadoras de enxerto gengival livre (a) em vista oclusal e (b) em vista aproximada.

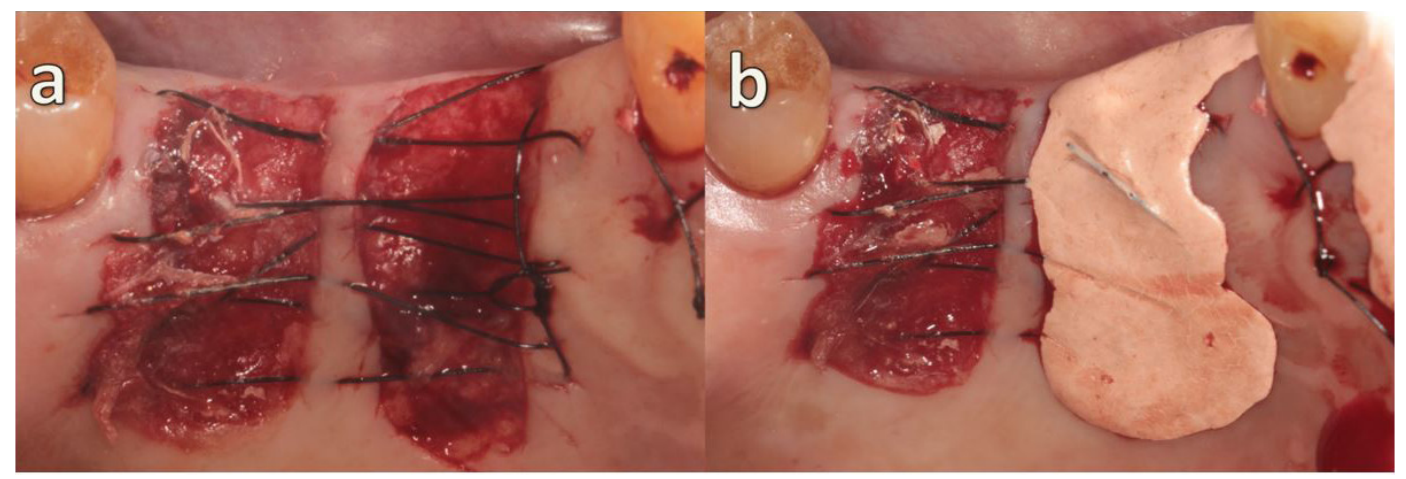

Figura 2. Aspecto da área doadora de enxerto gengival livre após a sutura com fio de nylon 4.0 (a). O leito da esquerda é o distal, que está recoberto com cianoacrilato, e o (b) da direita é o mesial, que foi recoberto com cimento cirúrgico. 
enquanto a mais mesial foi recoberta por cimento cirúrgico periodontal (Perio-Bond; Dentsply, Petrópolis, RJ, Brasil) (Figura 2b). Para aplicação do cianoacrilato, o líquido foi pingado sobre uma espátula de cera número 7 esterilizada e vertido aos poucos sobre o leito, em um procedimento muito simples e rápido. $\mathrm{O}$ endurecimento foi instantâneo.

Após o procedimento cirúrgico, a paciente foi instruída sobre os cuidados pós-operatórios, com aplicação de bolsa de gelo extraoral, alimentação líquida e pastosa fria, manutenção de repouso nas primeiras 24 horas e enxágue suave com solução de digluconato de clorexidina a $0,12 \%$, de 12 em 12 horas, durante 1 minuto, por 7 dias, além de não escovar a área operada. Foram prescritas algumas medicações antibiótica (Amoxicilina $500 \mathrm{mg}$, via oral, de $8 \mathrm{em} 8$ horas, durante 7 dias), anti-inflamatória (Nimesulida 100mg, de $12 \mathrm{em}$ 12 horas, durante 5 dias) e analgésica (Paracetamol $750 \mathrm{mg}$, de $6 \mathrm{em} 6$, horas durante 5 dias). A paciente foi instruída a contatar o cirurgião em caso de suspeita de complicação pós-operatória.
Sete dias após o procedimento cirúrgico e com o retorno da paciente, observou-se que o cimento cirúrgico não estava no local e parte do cianoacrilato havia se desprendido da área no dia anterior (Figura 3a). A sutura foi removida (Figura 3b), e o cianoacrilato e o cimento cirúrgico, novamente acomodados nos mesmos leitos. A paciente relatou que ambos se soltaram dois dias após. Depois da realização da cirurgia, a paciente retornou para acompanhamento aos 14, 28 e 35 dias, sempre revelando semelhanças entre as áreas doadoras que haviam sido recobertas pelo cianoacrilato e cimento cirúrgico (Figuras 4 e 5).

\section{Discussão}

O presente estudo foi desenvolvido para relatar os efeitos do uso de cianoacrilato comparativamente ao cimento cirúrgico periodontal em áreas doadoras de enxerto gengival livre, na mesma sessão e na mesma paciente. O principal achado foi que, clinicamente, houve semelhança entre ambas as áreas recobertas com os dois tipos de material ao longo



Figura 3. Aspecto da área doadora sete dias após a cirurgia, (a) antes e (b) após a remoção da sutura.

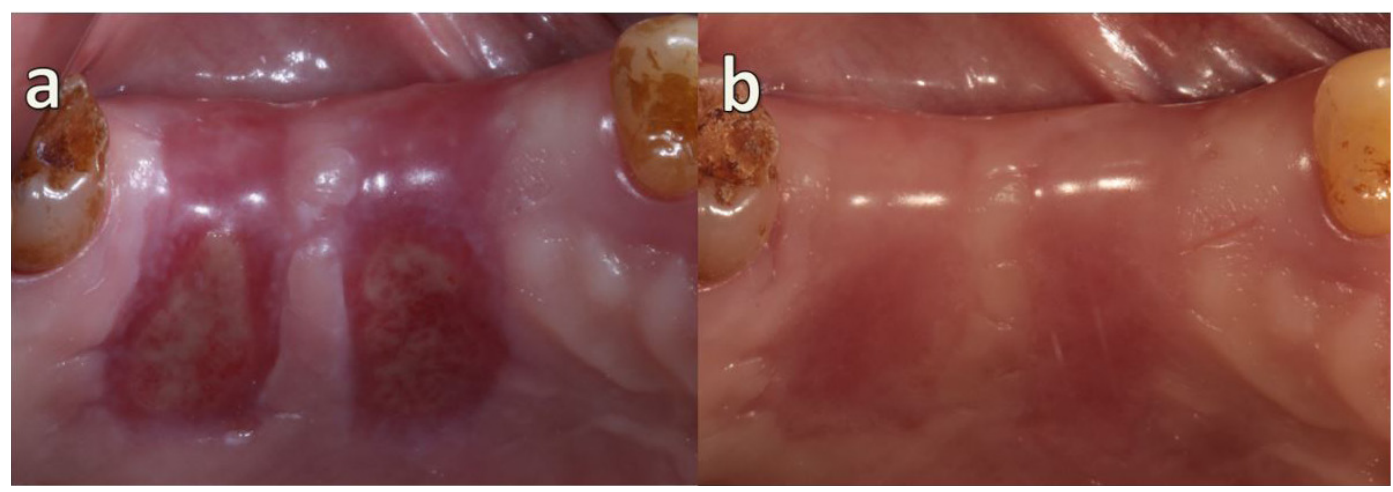

Figura 4. No pós-operatório, note a semelhança entre as áreas cirúrgicas após (a) 14 dias e (b) 28 dias. 


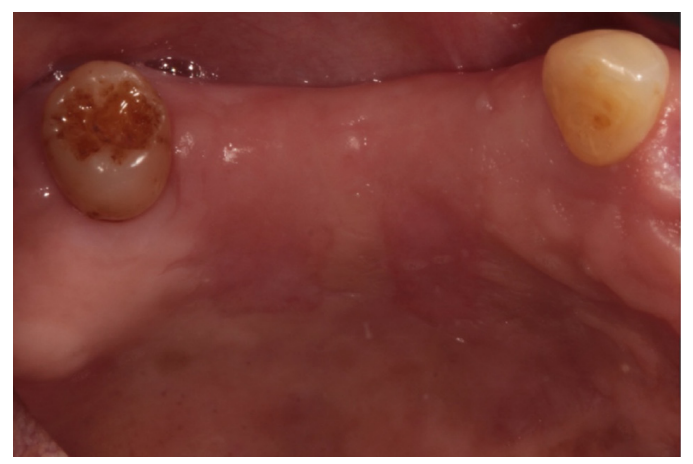

Figura 5. Aspecto pós-operatório de 35 dias.

dos 35 dias de acompanhamento. Essa afirmação contradiz o relato de Kulkarni et al. (2007), que avaliaram o selamento de retalhos rebatidos para raspagem e que perceberam aceleração do processo de reparo após o uso de cianoacrilato, principalmente nos sete primeiros dias. Porém corrobora o que foi descrito por Carvalho et al. (2007), que o emprego do cianoacrilato revelou-se benéfico pela facilidade de aplicação, habilidade de colar superfícies úmidas, pela rapidez de polimerização, por promover hemostasia imediata e pela redução do tempo operatório.

O uso desse adesivo em cirurgias de enxertos gengivais livres vem sendo relatado na literatura, como descrito por Forrest (1974), que comparou clinicamente o uso do cianoacrilato associado ou não à sutura, usando a técnica da boca dividida em 30 pacientes. O pesquisador concluiu que não houve diferenças significantes entre os dois grupos quanto ao processo de cicatrização, entretanto o cianoacrilato promoveu rápida hemostasia, menor desconforto comparado às suturas e melhor aceitação dos pacientes. Grisdale (1998) relatou um caso clínico em que a área doadora do enxerto gengival livre foi recoberta com sucesso usando o adesivo. Já no estudo de Barbosa et al. (2008), avaliaram-se as alterações dimensionais dos enxertos gengivais fixados com etil-cianoacrilato e recobertos por cimento cirúrgico. Esse recurso foi utilizado no leitos receptor e doador a fim de protegê-los e sem função de estabilização adicional, já que foram totalmente estabilizados com o adesivo, dispensando até mesmo o uso de suturas.

Embora Hallock (2001) tenha enfatizado que a resposta inflamatória desenvolvida pelo 2-octil-cianoacrilato seja leve, isto é, de menor intensidade que com fios convencionais, o que o faz mais vantajoso em relação ao seu uso, no presente caso optou-se pelo uso de sutura prévia à aplicação dos materiais estudados a fim de aumentar a retenção local. Mesmo assim, por ser uma área de grande atrito, o cimento cirúrgico acabou se descolando totalmente, e o cianoacrilato, parcialmente antes do sétimo dia. Assim, a utilização de adesivos sem sutura parece não se aplicar à área doadora de enxerto, com indicação limitada ao fechamento de lacerações e incisões em áreas de baixa tensão, pois proporciona uma resistência à tensão inferior à sutura convencional.

Poucos estudos demonstram a aplicabilidade do etil-cianoacrilato nas áreas doadoras do enxerto, como o palato. No estudo de Bhaskar et al. (1971), que empregaram spray à base de adesivo de cianoacrilato, tanto as áreas doadoras quanto as áreas receptoras de enxerto gengival livre proveniente do palato, em suínos e em humanos, estavam completamente reparadas após 21 dias e sem complicações pós-operatórias. No presente caso relatado, possivelmente pela dimensão das áreas doadoras e pelo fato de a paciente ser fumante, a epitelização foi observada apenas no acompanhamento de 28 dias.

Em um estudo comparativo entre cianoacrilatos e cimentos cirúrgicos em procedimentos com manutenção do periósteo intacto ou com exposição óssea, Ochstein et al. (1969) verificou melhores resultados com uso de cianoacrilato, tendendo este a melhor cicatrização. Porém, clinicamente, no presente caso relatado, não houve diferença significativa no processo de cicatrização entre o uso de um ou outro material, sugerindo que o cianoacrilato não foi eficiente em acelerar o processo de reparo. Adicionalmente, a profundidade do enxerto como foi realizada, com aproximadamente $2 \mathrm{~mm}$ de profundidade, não levou à exposição óssea, o que deve ter interferido positivamente na recuperação da paciente.

Mais testes deveriam ser feitos empregando dispositivos adicionais para aumentar a retenção em áreas de grande atrito, por exemplo, aparatos confeccionados usando fios ortodônticos. Além disso, sugere-se que sejam desenvolvidos estudos clínicos randomizados controlados, com cálculo de tamanho amostral, para garantir uma evidência científica mais forte (NEWMAN et al., 2003).

\section{Conclusão}

Com base nas observações clínicas, pode-se concluir que o cianoacrilato não trouxe benefícios adicionais à área doadora de enxerto de tecido 
conjuntivo, visto que o padrão de reparo foi muito semelhante ao do cimento cirúrgico, incluído similaridade quanto à hemostasia. Entretanto, seu uso pode ser justificado pela rapidez, pela facilidade de aplicação e pelo baixo custo.

\section{Referências}

BARBOSA, F.I.; ZENÓBIO, E.G.; COSTA, F.O.; CORRÊA, D.S.; CUNHA, F.A. Alterações dimensionais dos enxertos gengivais livres fixados por etil cianoacrilato. Revista Periodontia, v. 18, n. 1, p. 31-37, 2008.

BHASKAR, S.N.; BEASLEY, J.D. 3rd; CUTRIGHT, D.E.; PEREZ, B. Free mucosal grafts in miniature swine and man. Journal of Periodontology, v. 42, n. 6 , p. 322-330, 1971. PMid:5282572. http:// dx.doi.org/10.1902/jop.1971.42.6.322.

BHASKAR, S.N.; FRISCH, J.; MARGETIS, P.M.; LEONARD, F. Application of a new chemical adhesive in periodontic and oral surgery. Oral Surgery, Oral Medicine, and Oral Pathology, v. 22, n. 4, p. 526-535, 1966. PMid:5330649. http:// dx.doi.org/10.1016/0030-4220(66)90434-8.

BIER, C.A.; FIGUEIREDO, J.A.; DELLA BONA, A.; KOPPER, P.M.; VANNI, J.R.; BOPP, S. In vivo analysis of post space sealing with different adhesive materials. Journal of Applied Oral Science, v. 11, n. 3, p. 168-174, 2003. PMid:21394388. http:// dx.doi.org/10.1590/S1678-77572003000300003.

BUTLER, B.L. The subepitelial connective tissue graft with a vestibular releasing incision. Journal of Periodontology, v. 74, n. 6, p. 893-898, 2003. PMid:12887003. http://dx.doi.org/10.1902/ jop.2003.74.6.893.

CARVALHO, J.; NOVAK, M.J.; MOTA, L.F. Evaluation of the effect of subgingival placement of chlorhexidine chips as an adjunct to scaling and root planing. Journal of Periodontology, v. 78, n. 6, p. 997-1001, 2007. PMid:17539711. http:// dx.doi.org/10.1902/jop.2007.060122.

CHANG, P.C.; CHUNG, M.C.; WANG, Y.P.; CHIEN, L.Y.; LIM, J.C.; LIANG, K.; CHONG, L.Y.; KUO, Y.P.; CHEN, C.H.; CHIANG, H.C. Patterns of diabetic periodontal wound repair: a study using micro-computed tomography and immunohistochemistry. Journal of Periodontology, v. 83 , n. 5, p. 644-652, 2012. PMid:21966943. http://dx.doi.org/10.1902/jop.2011.110325.

COOVER, H.W.; JOYNER, F.B.; SHEARER JUNIOR, N.H.; WICKER JUNIOR, T.H. Chemistry and performance of cyanoacrylate adhesive. Journal of Society of Plastics Engineers, v. 15, p. 413-417, 1959.

ECHEVERRÍA, J.J.; MANZANARES, C. Guided tissue regeneration in severe periodontal defects in anterior teeth. Case reports. Journal of Periodontology, v. 66, n. 4, p. 295-300, 1995. PMid:7782985. http://dx.doi.org/10.1902/ jop.1995.66.4.295.

FARNOUSH, A. Techniques for the protection and coverage of the donor sites in free soft tissue grafts. Journal of Periodontology, v. 49, n. 8, p. 403-405, 1978. PMid:288907. http://dx.doi. org/10.1902/jop.1978.49.8.403.

FORREST, J.O. The use of cyanoacrylates in periodontal surgery. Journal of Periodontology, $\mathrm{v}$. 45, n. 4, p. 225-229, 1974. PMid:4594350. http:// dx.doi.org/10.1902/jop.1974.45.4.225.

GRISDALE, J. The use of cyanoacrylates in periodontal therapy. Journal - Canadian Dental Association, v. 64, n. 9, p. 632-633, 1998. PMid:9812430.

HABIB, A.; MEHANNA, A.; MEDRA, A. Cyanoacrylate: a handy tissue glue in maxilla facial surgery: our experience in Alexandria, Egypt. Journal of Maxillofacial and Oral Surgery, v. 12, n. 3, p. 243-247, 2013. PMid:24431849. http:// dx.doi.org/10.1007/s12663-012-0433-z.

HALLOCK, G.G. Expanded applications for octyl-2-cyanoacrylate as a tissue adhesive. Annals of Plastic Surgery, v. 46, n. 2, p. 185-189, 2001. PMid:11216619. http://dx.doi.org/10.1097/00000637200102000-00020.

KULKARNI, S.; DODWAD, V.; CHAVA, V. Healing of periodontal flaps when closed with silk sutures and N-butyl cyanoacrylate: a clinical and histological study. Indian Journal of Dental Research, v. 18, n. 2, p. 72-77, 2007. PMid:17502712. http:// dx.doi.org/10.4103/0970-9290.32424.

MATTICK, A. Use of tissue adhesives in the management of pediatric lacerations. Emergency 
Medicine Journal, v. 19, n. 5, p. 382-385, 2002. PMid:12204980. http://dx.doi.org/10.1136/ emj.19.5.382.

NEWMAN, M.G.; CATON, J.G.; GUNSOLLEY, J.C. The use of the evidence-based approach in a periodontal therapy contemporary science workshop. Annals of Periodontology, v. 8, n. 1, p. 1-11, 2003. PMid:14971245. http://dx.doi. org/10.1902/annals.2003.8.1.1.

OCHSTEIN, A.J.; HANSEN, N.M.; SWENSON, H.M. A comparative study of cyanoacrylate and other periodontal dressings on gingival surgical wound healing. J Periodontol., v. 40, n. 9, p. 515-520, 1969. PMid:5260864. http://dx.doi. org/10.1902/jop.1969.40.9.515.

OLIVEIRA, D.D.W.; MARQUES, D.P.; AGUIAR-CANTUÁRIA, I.C.; FLECHA, O.D.; GONÇALVES, P.F. Effect of surgical defect coverage on cervical dentin hypersensitivity and quality of life. Journal of Periodontology, v. 84, n. 6 , p. $768-775,2013$. PMid:22897654. http:// dx.doi.org/10.1902/jop.2012.120479.

PONTES, A.E.F.; GOMES, V.M.; RIBEIRO, F.S. Preservation of post-extraction socket without the use of bone substitutes is feasible? In: MARCANTONIO JUNIOR, E.; JAYME, S.J.; SHIBLI, J.A. (organizadores). Implantsupported restorations in anterior areas: from planning to execution. São Paulo: VM Cultural, 2014, p. 107-121.

REZENDE, M.L.; CONSOLARO, A.; SANT'ANA, A.C.; DAMANTE, C.A.; GREGHI, S.L.; PASSANEZI, E. Demineralization of the contacting surfaces in autologous onlay bone grafts improves bone formation and bone consolidation. Journal of Periodontology, v. 85, n. 5, p. e121-e129, 2014. PMid:24171500. http://dx.doi.org/10.1902/ jop.2013.130298.
SASKA, S.; GASPAR, A.M.M.; HOCHULIVIEIRA, E. Adesivos à base de cianoacrilato para síntese de tecido mole. Anais Brasileiros de Dermatologia, v. 84, n. 6, p. 595-92, 2009. PMid:20191169. http://dx.doi.org/10.1590/S036505962009000600003 .

STIMMELMAYR, M.; ALLEN, E.P.; REICHERT, T.E.; IGLHAUT, G. Use of a combination epithelized-subepithelial connective tissue graft for closure and soft tissue augmentation of an extraction site following ridge preservation or implant placement: description of a technique. The International Journal of Periodontics \& Restorative Dentistry, v. 30, n. 4, p. 375-381, 2010. PMid:20664839.

UEDA, E.L.; HOFLING-LIMA, A.L.; SOUSA, L.B.; TONGU, M.S.; YU, M.C.Z.; LIMA, A.A.S. Avaliação de um cianoacrilato quanto à esterilidade e atividade biocida. Arquivos Brasileiros de Oftalmologia, v. 67, n. 3, p. 397-400, 2004. http:// dx.doi.org/10.1590/S0004-27492004000300004

VELAZCO, G.; ORTIZ, R.; MARTÍNEZ, N.; ARELLANO, L. Biomateriales para el ciere de heridas en odontología. MedULA, v. 17, p. 69 73, 2008 .

VIERHOUT, B.P.; OTT, A.; REIJNEN, M.M.; OSKAM, J.; OTT, A.; VAN DENDUNGEN, J.J.; ZEEBREGTS, C.J. Cyanoacrylate skin microsealant for preventing surgical site infection after vascular surgery: a discontinued randomized clinical trial. Surgical Infections, v. 15, n. 4, p. 425-430, 2014. PMid:24840774. http://dx.doi. org/10.1089/sur.2013.191.

WEBER, S.C.; CHAPMAN, M.W. Adhesives in orthopedic surgery a review of the literature and in vitro bonding strengths of bone-bonding agents. Clinical Orthopaedics and Related Research, n. 191, 249-256, 1984. PMid:6388941. 